\title{
Comparisons of ICG-fluorescence with conventional tracers in sentinel lymph node biopsy for patients with early-stage breast cancer: A meta-analysis
}

\author{
RUI YIN ${ }^{1}$, LU-YU DING $^{2}$, QING-ZHONG WEI ${ }^{1}$, YA ZHOU $^{3}$, GUANG-YUAN TANG $^{3}$ and XUN ZHU ${ }^{3}$ \\ ${ }^{1}$ Department of General Surgery, Beijing Aerospace General Hospital, Beijing 100076; \\ ${ }^{2}$ Department of Psychiatry, The First Affiliated Hospital of China Medical University, Shenyang, Liaoning 110001; \\ ${ }^{3}$ Department of General Surgery, The Second Affiliated Hospital of Soochow University, Suzhou, Jiangsu 215004, P.R. China
}

Received November 18, 2019; Accepted August 24, 2020

DOI: $10.3892 / \mathrm{ol} .2020 .12375$

\begin{abstract}
Radioisotopes (RI) and blue dye (BD) are routinely used markers for staining during sentinel lymph node biopsy (SLNB) in breast cancer. Compared with traditional tracers, tracer performance of indocyanine green (ICG) has been controversial. A total of 21 studies were selected from the PubMed, EMBASE and Cochrane Library databases. Detection ability was judged based on four endpoints: i) The identification rate (IR) of the patients; ii) the IR of the sentinel lymph nodes (SLNs); iii) the IR of the positive SLNs; and iv) the false negative rate (FNR). Compared with $\mathrm{BD}$, ICG was superior in terms of the IR of the patients [odds ratio $(\mathrm{OR})=7.17 ; 95 \% \mathrm{CI}, 3.98-12.94)$, the IR of the SLNs $(\mathrm{OR}=8.84 ; 95 \% \mathrm{CI}, 6.71-11.66)$ and $\mathrm{FNR}(\mathrm{OR}=0.20 ; 95 \% \mathrm{CI}$, 0.08-0.48) using a fixed-effects model. There was a significant difference in both the IR of the positive SLNs (OR=21.32; 95\% CI, 2.84-160.14) and FNR (OR=0.46; 95\% CI, 0.23-0.91) in the ICG vs. RI group. Furthermore, when using ICG at the recommended dose, a significant difference was found in the IR of the patients $(\mathrm{OR}=1.77 ; 95 \% \mathrm{CI}, 1.09-2.85)$ and the IR of the SLNs $(\mathrm{OR}=21.62 ; 95 \% \mathrm{CI}, 5.23-89.43)$ using a fixed-effects model. In the ICG vs. BD combined with RI group, there were no differences in either the IR of the patients $(\mathrm{OR}=5.10 ; 95 \% \mathrm{CI}, 0.24-107.48)$ or the IR of SLNs (OR=5.10; $95 \%$ CI, 0.60-256.66). In conclusion, ICG was a better tracer
\end{abstract}

Correspondence to: Dr Xun Zhu, Department of General Surgery, The Second Affiliated Hospital of Soochow University, 1055 SanXiang Road, Suzhou, Jiangsu 215004, P.R. China

E-mail: szdxfsdeyyzhuxun@163.com

Abbreviations: SLNB, sentinel lymph node biopsy; RI, radioisotopes; $\mathrm{BD}$, blue dye; ICG, indocyanine green; IR, identification rate; SLN, sentinel lymph nodes; FNR, false negative rate

Key words: sentinel lymph node biopsy, indocyanine green, radioisotope, blue dye compared with BD or RI alone and was not a worse tracer compared with BD combined with RI. The use of the recommended dose of ICG had an improved tracer effect. ICG is expected to be widely used in SLNB in view of its clinical advantages.

\section{Introduction}

The sentinel lymph node biopsy (SLNB) method has been widely used to evaluate axillary lymphatic status. Compared with SLNB, the incidence and severity of postoperative complications, including lymphedema, swelling of the arm and sensory loss, caused by axillary lymph node dissection are higher (1). Since Krag et al (2) first reported the use of radioisotopes (RI) in 1993 and Giuliano et al (3) reported using blue dye (BD) in 1994, the combination of BD and RI has been used as a standard technique to increase the detection rate of sentinel lymph nodes (4). Certain clinical limitations of BD and RI, including allergies and radioactivity, have prompted the development of other tracer technologies (4). Indocyanine green (ICG)-guided SLNB has been employed for the staging of the axillary lymphatic status since 2005 (4) and numerous clinical trials and cohort studies have shown that ICG is a promising technology in patients with early stage breast cancer $(4,5)$. Though the majority of these data supported the conclusion that using ICG was not worse in SLNB compared with other tracers, some studies reported that ICG is a less effective tracer. A systematic review performed in 2014 stated that ICG was significantly better than BD with regard to improving sentinel lymph node identification (5). However, a more recent systematic review reported that the ICG fluorescence method demonstrated improved axillary staging compared with the RI method (6). Therefore, it is difficult to draw a clear conclusion, because the results for comparing ICG with traditional tracers are usually contradictory. To the best of our knowledge, whether ICG can be applied clinically as a valid tracer and replace traditional standard techniques has not yet been established.

Considering the lack of conclusions regarding the clinical utility of ICG, the present study collected data from relevant 
randomized controlled trials and cohort studies and compared the tracer ability of ICG with BD and RI, both individually and in combination. The aim of the present study was to confirm whether ICG can act as a better tracer agent compared with conventional techniques.

\section{Materials and methods}

Search strategy. The present study was performed according to the Preferred Reporting Items for Systematic Reviews and Meta-Analyses statement (7). To assess the level of sensitivity, the main international electronic data sources, including PubMed (https://pubmed.ncbi.nlm.nih.gov), EMBASE (http://www.embase.com) and the Cochrane Library (https://www.cochranelibrary.com), were searched simultaneously.

The terms 'breast cancer', 'sentinel lymph node biopsy', 'blue dye', 'indocyanine green', 'radioisotope' and similar terms were cross-searched using the following search algorithms: ((( breast cancer OR breast neoplasms OR breast carcinoma)) AND (SLNB OR sentinel lymph node biopsy)) AND (indocyanine green OR ICG OR radioisotope OR RI OR blue dye OR BD))). All relevant studies were published between May 2009 and March 2017.

Selection criteria. The current meta-analysis included all studies meeting the following criteria: i) Patients: Patients with clinical axillary lymph node-negative early breast cancer; ii) research methods: SLNB using ICG-guided near-infrared fluorescence imaging, using $\geq$ two tracers and using the patient as the self control; iii) study type: Cohort study or randomized clinical trial; and iv) language: English.

The following exclusion criteria was used: i) Meeting abstracts and studies that did not contain comparisons of ICG with other tracers and articles with neoadjuvant therapy; ii) study sample sizes $<10$; iii) studies that performed axillary reverse mapping; and iv) studies that did not use the patients as their own controls.

All eligible studies were categorized into three groups: i) ICG vs. BD; ii) ICG vs. RI; and iii) ICG vs. BD and RI. The outcomes considered included studies that comprised the identification rate (IR) of the patients, the IR of the sentinel lymph nodes (SLNs) and the IR of the positive SLNs and false negative rate (FNR).

Data extraction. In the present study, RY and $\mathrm{XZ}$ assessed and screened the literature independently. Titles and abstracts were first inspected, then full texts of potentially relevant publications were obtained and screened. Any discrepancy was resolved by discussion between the reviewers. Disagreements were solved by full discussion until consensus was reached.

The characteristics of the cohort and randomized clinical studies, including first author, year of publication, number of cases and controls, device, dose of tracers and detection outcomes for each study are presented in Table I. Different equipment, including PhotoDynamic Eye (PDE), Mini-fluorescence-assisted resection and exploration (Mini-FLARE) and a charge-coupled camera (CCD) were used.
Quality assessment. The quality and bias risk of the selected papers were critically appraised separately by RY and LD. A quality assessment was performed for each of the eligible studies using the validated Newcastle-Ottawa Quality Assessment Scale (NOS) (8). This scale is composed of eight items that assess patient selection, study comparability and outcome with scores ranging 0-9. In the present meta-analysis, studies with a score of $\geq 6$ were graded as high quality. The quality of the included studies assessed by NOS are presented in Table II. Disagreements were discussed until a consensus was reached.

Statistical analysis. Dichotomous results were summarized as pooled odds ratios (ORs) and 95\% CIs around the point estimates. OR was abstracted or calculated to quantitatively evaluate the association between ICG and the other tracers. The overall pooled effect was assessed using the z-statistic with $\mathrm{P} \leq 0.05$ indicating a statistically significantly difference. Heterogeneity between studies was assessed by the ' $\mathrm{I}^{2}$ ' value. When $\mathrm{I}^{2} \geq 50 \%$ or the $\mathrm{P}$-value for the $\mathrm{I}^{2}$ statistic was $<0.05$, which indicated significant heterogeneity across the studies, the pooled estimate was calculated using a random-effects model. If the data were contrary, a fixed-effect model was adopted. Statistical heterogeneity was explored using the $\chi^{2}$ and Tau ${ }^{2}$ statistical tests. Subgroup analysis was based on the ICG dose, and studies were divided into 'standard dose of reference', 'more than standard dose of reference' and 'less than standard dose of reference'. All statistical analyses were performed using RevMan software (version 5.3; The Nordic Cochrane Centre) and Stata software (version 15.1; StataCorp LLC). Forest plot and receiver operating characteristic plot were obtained to evaluate the sensitivity and specificity of subgroup. Funnel plots with Egger's test were used to identify publication bias. All analyses were based on previous published studies; therefore, no ethical approval or patient consent was required.

\section{Results}

Characteristics of eligible studies. A total of 262 articles were retrieved from PubMed, EMBASE and The Cochrane Library and, ultimately, 21 studies were selected with a total of 2,499 patients for detailed assessment (9-29). A flow diagram of the selection process is presented in Fig. 1. All the selected studies were scored $\geq 6$ according to NOS (Table II).

Meta-analysis results. Comparison of SLNB using BD, RI and ICG was performed in 21 studies and analyzed using four outcome variables. ICG was compared with $\mathrm{BD}$ alone, $\mathrm{RI}$ alone and RI with BD separately. The results of the meta-analysis are presented in Table III.

$I C G$ vs. RI

IR of patients. A total of 13 studies involving 1,731 patients reported the identification rate for patients using ICG and RI, which revealed no differences in the random-effects model ( $\mathrm{OR}=1.63$; 95\% CI, 0.65-4.10; $\mathrm{P}=0.30$; Fig. 2A). The heterogeneities of the detection rate of these patients were high $\left(\mathrm{I}^{2}=55 \% ; \mathrm{P}=0.02\right)$.

Taking the high heterogeneities into account, the concentration of ICG was variable and ranged from $0.1-10 \mathrm{mg} / \mathrm{ml}$. 


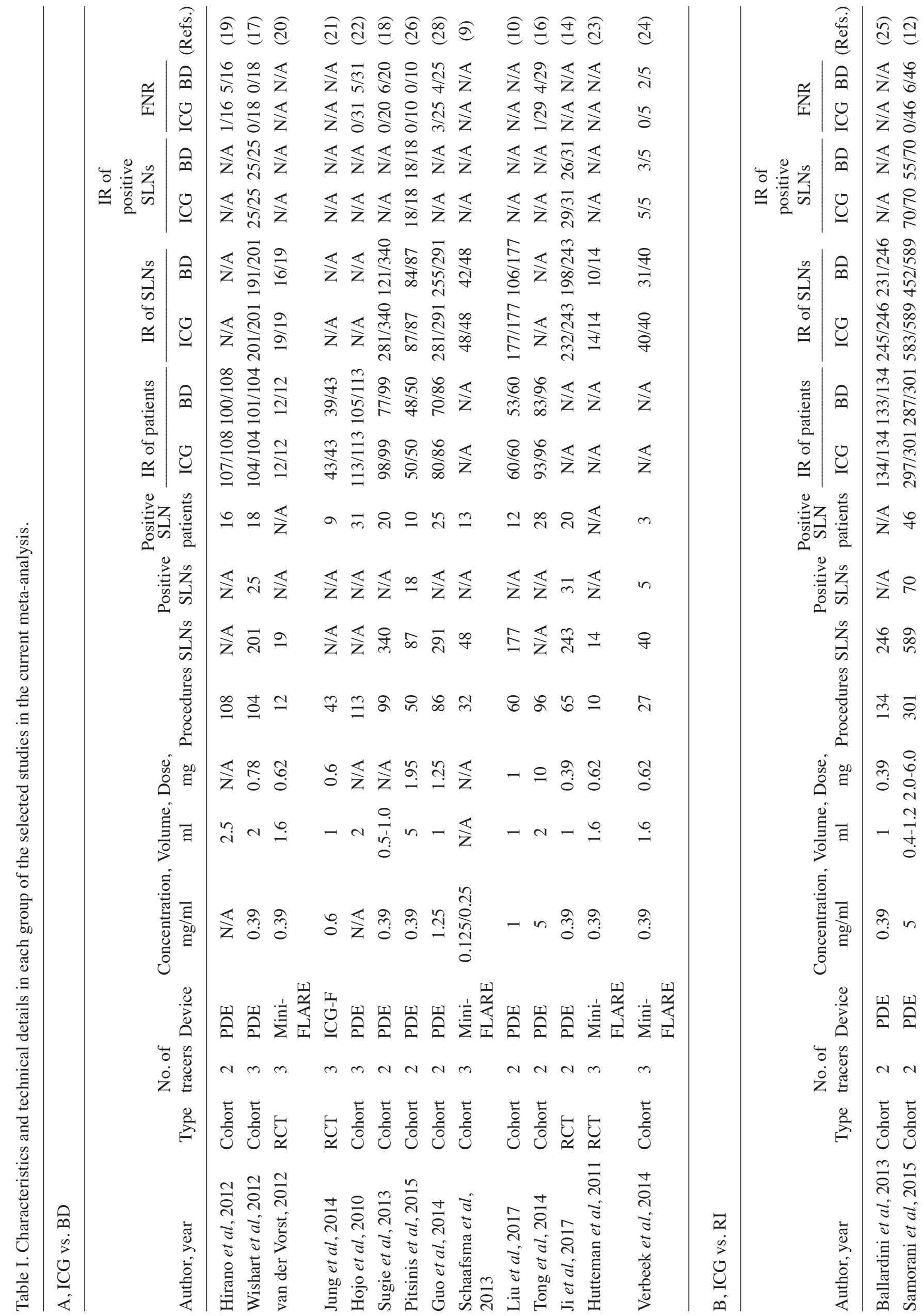



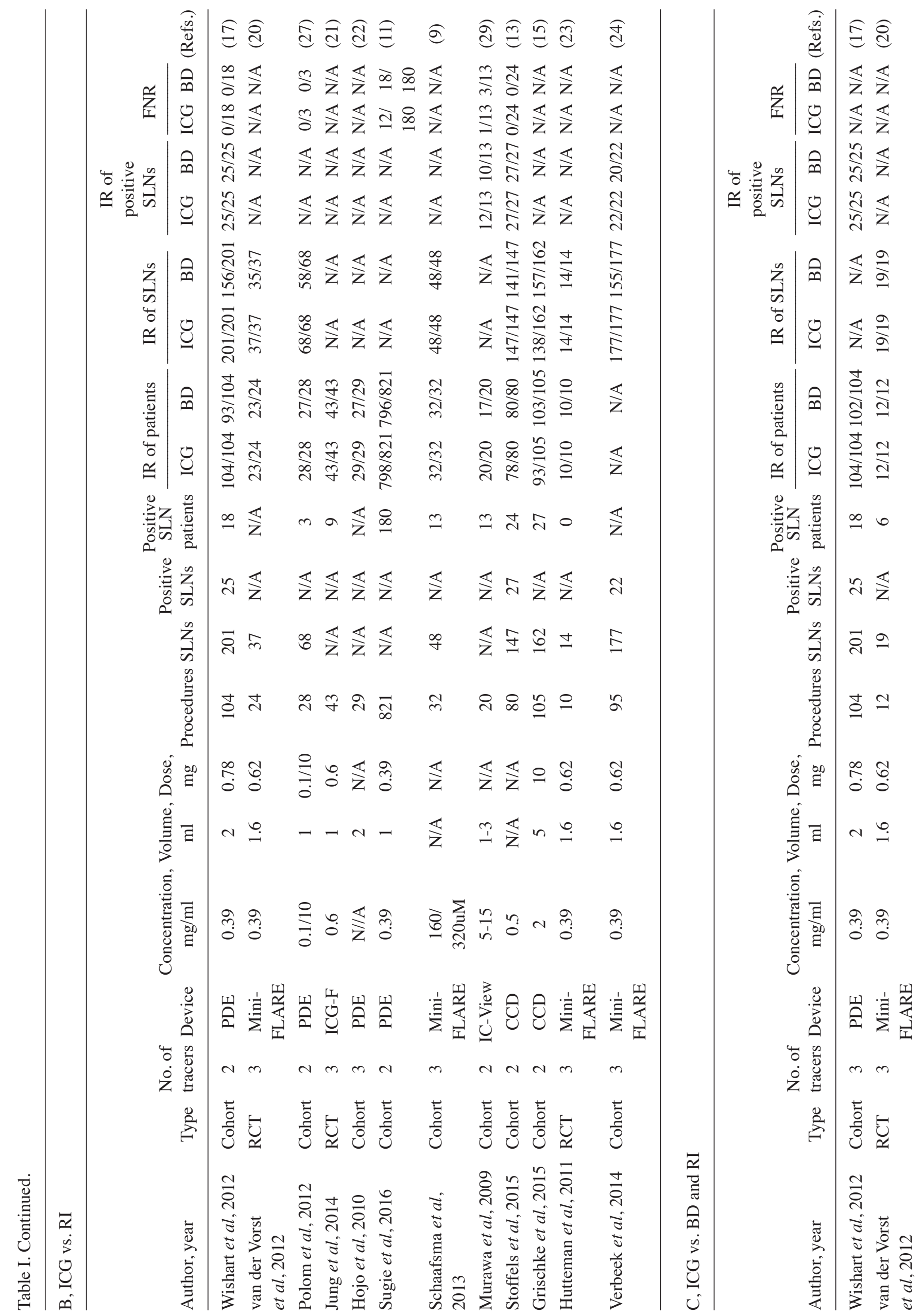
Therefore, a subgroup analysis was performed based on a previous study by Mieog et al (30), which concluded that the optimal dose of ICG was 400-800 $\mu \mathrm{M}$. The fixed-effects model was used to calculate the results and demonstrated that the detection rate of patients with ICG was significantly higher compared with that of RI and the heterogeneity was decreased in the standard dose subgroup (OR=1.77; 95\% CI, 1.09-2.85; $\mathrm{P}=0.02$; Fig. 2B).

IR of SLNs. A total of 10 studies with 881 patients investigated the detection rate for SLNs between ICG and RI, and revealed significant differences in the random-effects model $(\mathrm{OR}=12.05$; 95\% CI, 1.57-92.74; $\mathrm{P}=0.02$; Fig. 3A). Considering the significant heterogeneity $\left(\mathrm{I}^{2}=90 \% ; \mathrm{P}<0.01\right)$, a subgroup analysis was performed according to the dose of ICG, and the results demonstrated that the SLN detection rate of ICG was significantly higher compared with that of the standard dose of RI $(\mathrm{OR}=21.62$; 95\% CI, 5.23-89.43; P<0.0001; Fig. 3B) and $\mathrm{I}^{2}$ dropped from 90 to $0 \%$, which indicated that the heterogeneity comes from the high dose group. Furthermore, a sensitivity and specificity analysis of ICG and RI lymph node detection was performed in the recommended dose group. A total of three studies including 961 lymph nodes reported the accuracy of ICG in lymph node detection was higher compared with RI (Fig. 4).

IR of positive SLNs. A total of four studies consisting of 744 patients reported the detection rate of positive SLNs between ICG and RI, which revealed significant differences in the fixed-effects model (OR=21.32; 95\% CI, 2.84-160.14; $\mathrm{P}=0.003$; Fig. 5A), indicating that ICG had an improved identification rate of positive SLNs compared with RI.

$F N R$. A total of five studies with 1,326 patients reported the FNR between ICG and RI, which revealed significant differences in the fixed-effects model (OR=0.46; 95\% CI 0.23-0.91; $\mathrm{P}=0.03$; Fig. 5B).

ICG vs. BD

IR of patients. A total of 10 studies that included 771 patients reported the detection rate of patients using ICG and BD. The results demonstrated a significant difference in the fixed-effects model (OR=7.17; 95\% CI, 3.98-12.94; $\mathrm{P}<0.00001$; Fig. 6A), indicating that the detection rate of ICG was higher compared with BD. There was no heterogeneity $\left(\mathrm{I}^{2}=0 \%\right.$. $\mathrm{P}=0.68$; Fig. 6A).

IR of SLNs. A total of 10 studies involving 449 patients reported the detection rate for SLNs between ICG and BD. The results identified 1,460 SLNs and the mean number of SLNs (the number of lymph nodes detected/total number of patients) retrieved using ICG was 3.07, which was higher compared with the number of SLNs retrieved using BD (2.35). The fixed-effects model (OR=8.84; 95\% CI, 6.71-11.66; $\mathrm{P}<0.00001$; Fig. 6B) was used and significant differences between ICG and BD were observed, demonstrating that ICG had a statistically higher detection rate of SLNs. The heterogeneity was low with $\mathrm{I}^{2}=37 \%$ and $\mathrm{P}=0.11$ (Fig. 6B).

$I R$ of positive SLNS. A total of four studies involving 246 patients reported the detection rate for positive SLNs 
Table II. The quality of the included studies as assessed by the Newcastle-Ottawa Quality Assessment Scale.

\begin{tabular}{|c|c|c|c|c|c|c|c|c|c|c|c|}
\hline \multirow{2}{*}{$\begin{array}{l}\text { Author, year } \\
\text { Hirano et al, } 2012\end{array}$} & \multicolumn{4}{|c|}{ Selection } & \multicolumn{2}{|c|}{$\begin{array}{l}\text { Compa- } \\
\text { rability }\end{array}$} & \multicolumn{3}{|c|}{ Outcome } & \multirow{2}{*}{$\begin{array}{c}\text { Score } \\
9\end{array}$} & \multirow{2}{*}{$\frac{\text { (Refs.) }}{(19)}$} \\
\hline & $\sum\langle$ & is & $i$ & $i s$ & $\sum$ & $i$ & $i$ & $\sum$ & ț & & \\
\hline Wishart et al, 2012 & 柁 & is & $i$ & 诧 & $\sum$ & $\sum$ & $\sum \hat{r}$ & & & 7 & (17) \\
\hline van der Vorst et al, 2012 & $i s$ & is & is & $\hat{z}$ & $\dot{s}$ & $i$ & $i t$ & & & 7 & $(20)$ \\
\hline Jung et al, 2014 & $i s$ & $i t$ & $i$ & $i s$ & $\sum$ & $\sum$ & $i t$ & $i$ & & 8 & $(21)$ \\
\hline Hojo et al, 2010 & is & 访 & $\sum$ & $\sum\langle$ & $\sum$ & $\sum$ & ist & & & 7 & $(22)$ \\
\hline Sugie et al, 2013 & $i t$ & $\hat{\imath}$ & $i s$ & $i t$ & $\dot{t}$ & $i$ & $i t$ & $i$ & & 8 & (18) \\
\hline Pitsinis et al, 2015 & is & 为 & $i s$ & $\sum\langle$ & $\sum$ & $\sum$ & 柁 & is & & 8 & (26) \\
\hline Guo et al, 2014 & its & 岤 & $i$ & it & $\sum$ & $\sum$ & $\sum t$ & & & 7 & $(28)$ \\
\hline Schaafsma et al, 2013 & $\hat{s}$ & 牙 & $i s$ & $\hat{\tau}$ & $\hat{s}$ & 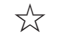 & $\hat{\imath}$ & & & 7 & (9) \\
\hline Liu et al, 2017 & $i s$ & 为 & $i$ & $i v$ & 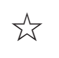 & $i$ & $i t$ & is & 访 & 9 & (10) \\
\hline Tong et al, 2014 & $i s$ & 拧 & $i s$ & $i s$ & $\sum$ & $\sum$ & $i$ & & & 7 & (16) \\
\hline Ji et al, 2017 & is & 岤 & $i$ & is & $\sum$ & $\sum$ & $i t$ & $i$ & & 8 & (14) \\
\hline Hutteman et al, 2011 & is & 论 & $i$ & is & 访 & $\sum$ & is & & & 7 & (23) \\
\hline Verbeek et al, 2014 & $i t$ & $\hat{2}$ & $\hat{s}$ & $i t$ & $\dot{s}$ & $\dot{\xi}$ & $i t$ & & & 7 & (24) \\
\hline Ballardini et al, 2013 & $i s$ & 拧 & $i s$ & $i s$ & $\sum$ & $\sum$ & $i$ & & & 7 & $(25)$ \\
\hline Samorani et al, 2015 & is & is & $i$ & is & $\sum$ & $\sum$ & $i t$ & & & 7 & (12) \\
\hline Polom et al, 2012 & $i s$ & $\dot{\omega}$ & $i s$ & $i s$ & $\dot{s}$ & $i s$ & $i t$ & & & 7 & (27) \\
\hline Sugie et al, 2016 & $i s$ & $i$ & $i s$ & $i t$ & $\sum$ & $\sum$ & $i$ & & & 7 & (11) \\
\hline Murawa et al, 2009 & is & $i$ & $i$ & is & 论 & $i$ & its & & & 7 & (29) \\
\hline Grischke et al, 2015 & $\hat{z}$ & is & $\hat{z}$ & $i t$ & $\sum$ & & $i$ & & & 6 & $(15)$ \\
\hline Stoffels et al, 2015 & $i s$ & 访 & $i s$ & $i s$ & 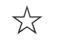 & $i 2$ & $i t$ & & & 7 & (13) \\
\hline
\end{tabular}

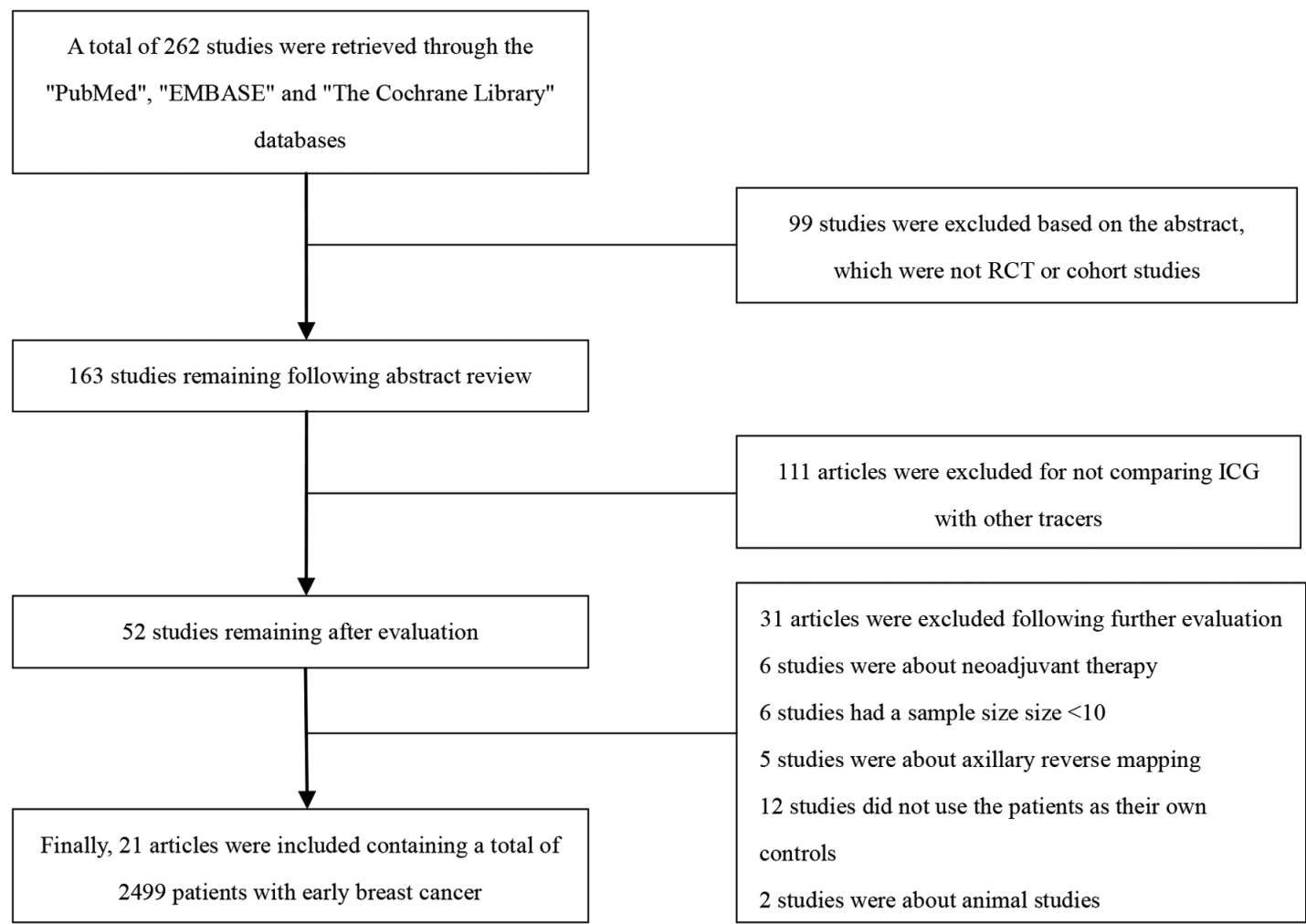

Figure 1. Flow diagram for the selection of the including studies. RCT, randomized clinical trial. 
Table III. Results of the meta-analysis.

\begin{tabular}{|c|c|c|c|c|}
\hline \multirow[b]{2}{*}{ Variable } & \multicolumn{2}{|c|}{ Pooled estimates } & \multicolumn{2}{|c|}{ Heterogeneity } \\
\hline & OR & $95 \% \mathrm{CI}$ & $\mathrm{I}^{2}, \%$ & P-value \\
\hline \multicolumn{5}{|l|}{ IR of patients } \\
\hline ICG vs. BD & 7.17 & $3.98-12.94$ & 0 & 0.68 \\
\hline ICG vs. RI & 1.63 & $0.65-4.10$ & 55 & 0.02 \\
\hline Standard dose of reference & 1.77 & $1.09-2.85$ & 47 & 0.11 \\
\hline More than standard dose & 0.86 & $0.41-1.83$ & 71 & 0.02 \\
\hline $\begin{array}{l}\text { Less than standard dose } \\
\text { ICG vs. BD and RI }\end{array}$ & $\mathrm{N} / \mathrm{A}$ & N/A & $\mathrm{N} / \mathrm{A}$ & N/A \\
\hline \multicolumn{5}{|l|}{ IR of SLNs } \\
\hline ICG vs. BD & 8.84 & $6.71-11.66$ & 37 & 0.11 \\
\hline ICG vs. RI & 12.05 & $1.57-92.74$ & 90 & $<0.05$ \\
\hline Standard dose of reference & 21.62 & $5.23-89.43$ & 0 & 0.53 \\
\hline More than standard dose & 2.50 & $1.56-3.99$ & 95 & $<0.05$ \\
\hline Less than standard dose & N/A & $\mathrm{N} / \mathrm{A}$ & $\mathrm{N} / \mathrm{A}$ & $\mathrm{N} / \mathrm{A}$ \\
\hline \multicolumn{5}{|l|}{ IR of positive SLNs } \\
\hline ICG vs. BD & 3.54 & $0.78-16.06$ & 0 & 0.59 \\
\hline ICG vs. RI & 21.32 & $2.85-160.14$ & 0 & 0.34 \\
\hline ICG vs. BD and RI & $\mathrm{N} / \mathrm{A}$ & $\mathrm{N} / \mathrm{A}$ & N/A & N/A \\
\hline \multicolumn{5}{|l|}{ FNR } \\
\hline ICG vs. BD & 0.20 & $0.08-0.48$ & 0 & 0.59 \\
\hline ICG vs. RI & 0.46 & $0.23-0.91$ & 23 & 0.27 \\
\hline ICG vs. BD and RI & N/A & N/A & N/A & $\mathrm{N} / \mathrm{A}$ \\
\hline
\end{tabular}

OR, odds ratio; IR, identification rate; ICG, indocyanine green; BD, blue dye; RI, radioisotope; N/A, not available; SLNs, sentinel lymph nodes; FNR, false negative rate.

between ICG and BD. The results revealed no differences in the fixed-effects model $(\mathrm{OR}=3.54 ; 95 \% \mathrm{CI}, 0.78-16.06 ; \mathrm{P}=0.10$; Fig. 6C). However, the overall detection rate of positive SLNs (the number of positive lymph nodes detected/total positive lymph nodes) using ICG was $97.5 \%$ and the detection rate of using BD was $91.1 \%$. No heterogeneity was observed at $\mathrm{I}^{2}=0 \%$ and $\mathrm{P}=0.59$.

$F N R$. A total of eight studies including 683 patients reported the FNR between ICG and BD, a total of 154 positive SLNs were identified and the overall FNR (the number of positive lymph nodes not detected/total positive lymph nodes) using ICG was $3.25 \%$. This was lower than the FNR of using $\mathrm{BD}$, which was $16.88 \%$. Using the fixed-effects model, the results revealed significant differences $(\mathrm{OR}=0.20 ; 95 \% \mathrm{CI}$, 0.08-0.48; P=0.0004; Fig. 6D), which demonstrated that ICG had a lower FNR compared with BD. There was no heterogeneity at $\mathrm{I}^{2}=0 \%$ and $\mathrm{P}=0.59$. For further analysis, sensitivity and specificity analyses on this group of studies were performed and the results demonstrated that the accuracy of ICG was higher compared with that of BD in lymph node detection (Fig. 7).

$I C G$ vs $B D$ and $R I$. A total of four studies including 169 patients reported the detection rate of patients with ICG and BD combined with RI. The identification rate using the ICG method was $100 \%$, while the identification rate of patients using the BD combined with the RI method ranged from $98-100 \%$. No difference was reported in the fixed-effects model $(\mathrm{OR}=5.10 ; 95 \%$ CI, 0.24-107.48; Fig. 8A). Therefore, heterogeneity was not applicable.

Only two studies with 22 patients provided data on the detection rate of SLNs with ICG and BD combined with RI. The mean number of SLNs (the number of lymph nodes detected/total number of patients) retrieved using ICG was 1.50 , which was more compared with the number detected using BD combined with RI at 1.32. No difference was revealed in the fixed-effects model $(\mathrm{OR}=12.43$; 95\% CI, 0.60-256.66; Fig. 8B), with heterogeneity not being applicable.

For groups with $<10$ studies, the publication bias was not assessed. The Egger's test was performed using the software Stata. No obvious publication bias was found since $\mathrm{P}=0.700$ (Fig. 9A) and 0.259 (Fig. 9B) for IR of patients and IR of SLNs, respectively.

\section{Discussion}

The number of lymph nodes obtained from SLNB is used as a guide to decide whether or not to continue subsequent 
A

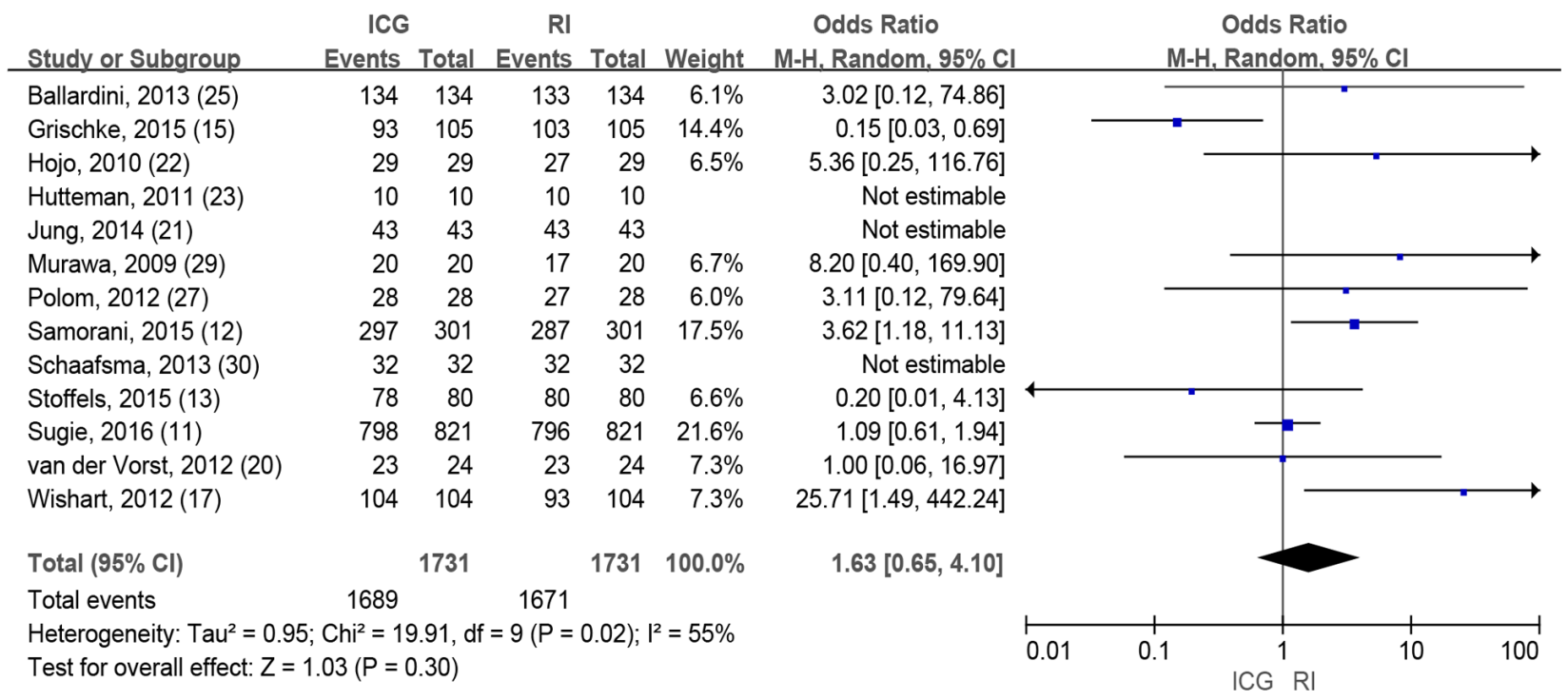

B

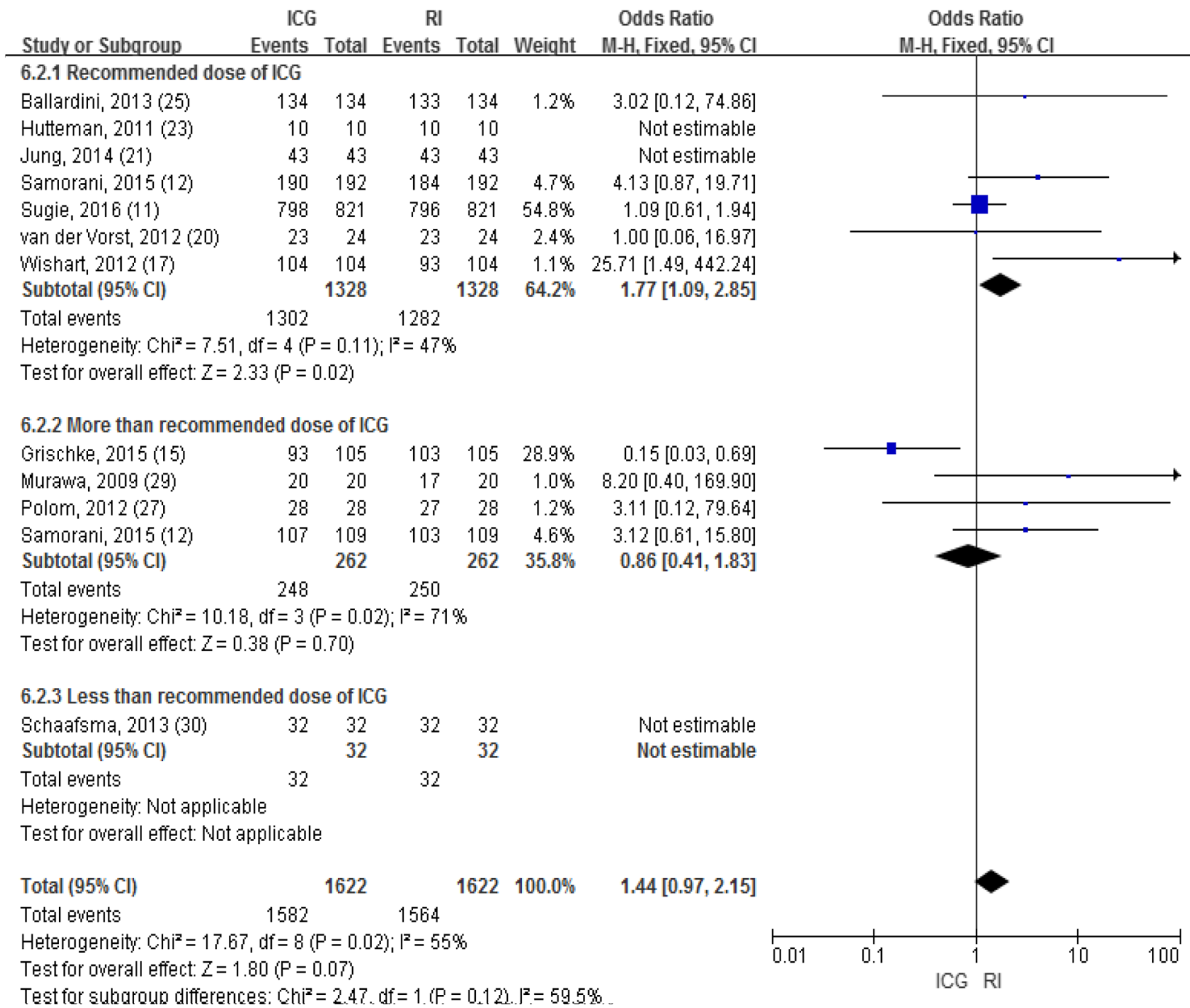

Figure 2. Comparison of ICG and RI in the IR of patients. (A) Results prior to grouping ICG doses. (B) Results following grouping of ICG doses. ICG, indocyanine green; RI, radioisotope; IR, identification rate; M-H, Mantel-Haensze.

axillary lymph node dissection according to the latest National Comprehensive Cancer Network guidelines (10). Although the range of the armpit area subjected to surgery has been a decreasing, the accuracy of lymph node biopsies is becoming increasingly important and obtaining effective and convenient tracers are particularly important for surgeons (11). 
A

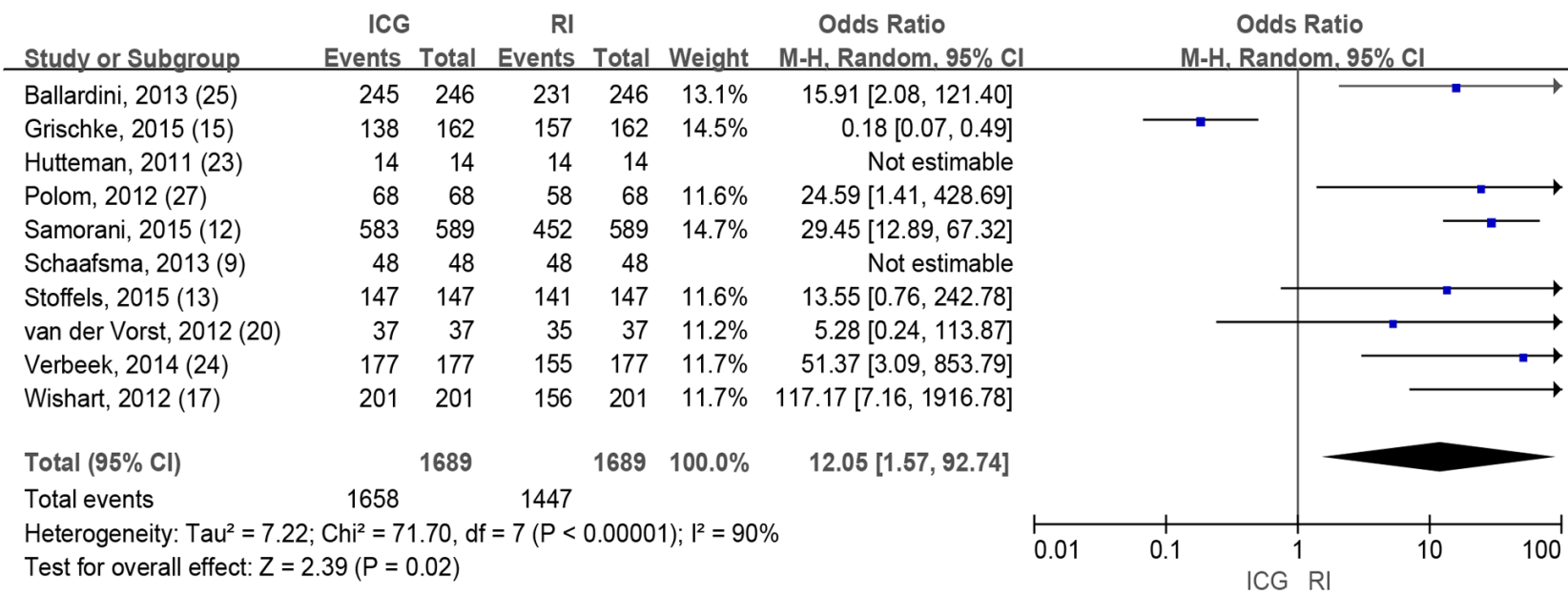

B

\begin{tabular}{lrrrrrr} 
& \multicolumn{1}{c}{ ICG } & \multicolumn{2}{c}{ RI } & & Odds Ratio \\
Study or Subqroup & Events & Total & Events & Total & Weight & M-H, Fixed, 95\% C \\
\hline 2.2 .1 Recommended dose of ICG & & & & & \\
Ballardini, 2013(25) & 245 & 246 & 231 & 246 & $3.6 \%$ & $15.91[2.08,121.40]$ \\
Hutteman, 2011 (23) & 14 & 14 & 14 & 14 & & Not estimable \\
van der Vorst, 2012(20) & 37 & 37 & 35 & 37 & $1.8 \%$ & $5.28[0.24,113.87]$ \\
Verbeek, 2014(24) & 177 & 177 & 155 & 177 & $1.7 \%$ & $51.37[3.09,853.79]$ \\
Subtotal (95\% Cl) & & 474 & & 474 & $7.1 \%$ & $21.62[5.23,89.43]$ \\
Total events & 473 & & 435 & & &
\end{tabular}

Heterogeneity: $\mathrm{Ch}^{2}=1.26, \mathrm{df}=2(\mathrm{P}=0.53) ; \mathrm{I}^{2}=0 \%$

Test for owerall effect: $Z=4.24(\mathrm{P}=0.0001)$

2.2.2 More than recommended dose of ICG

$\begin{array}{lrrrrrr}\text { Grischke, 2015(15) } & 138 & 162 & 157 & 162 & 89.7 \% & 0.19[0.07,0.49] \\ \text { Polom, 2012(27) } & 68 & 68 & 58 & 68 & 1.6 \% & 24.59[1.41,428.69] \\ \text { Wishart, 2012(17) } & 201 & 201 & 158 & 201 & 1.5 \% & 110.60[6.76,1810.56] \\ \text { Subtotal }(95 \% \mathrm{Cl}) & & 431 & & 431 & 92.9 \% & 2.41[1.51,3.87] \\ \text { Total everts } & 407 & & 373 & & & \end{array}$

Heterogeneity: $\mathrm{Ch}^{2}=35.77, \mathrm{df}=2(\mathrm{P}=0.00001) ; \mathrm{l}^{2}=94 \%$

Test for owerall effect: $Z=3.66(P=0.0003)$

2.2.3 Less than recommended dose of ICG

$\begin{array}{llllll}\text { Schaafsma, 2013 (9) } & 48 & 48 & 48 & 48 & \text { Not estimable } \\ \text { Subtotal }(95 \% \mathrm{Cl}) & & 48 & & 48 & \text { Not estimable } \\ \text { Total events } & 48 & & 48 & & \end{array}$

Heterogeneity: Not applicable

Test for owerall effect: Not applicable

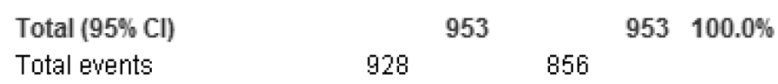

Heterogeneity: $\mathrm{Chi}^{2}=48.42, \mathrm{df}=5(\mathrm{P}<0.00001) ; \mathrm{I}^{2}=90 \%$

Test for owerall effect: $Z=6.06$ ( $P \leq 0.00001)$

Test for subaroun differences: $\mathrm{Chi}^{2}=8.25 . \mathrm{df}=1(\mathrm{P}=0.004)^{2} \mathrm{I}^{2}=87.9 \%$

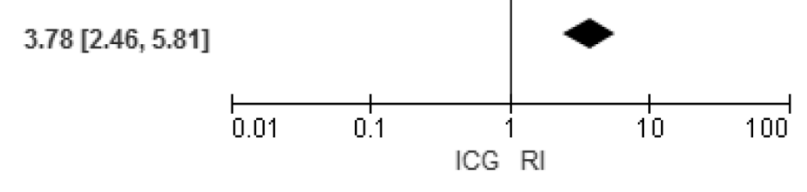

Figure 3. Comparison of ICG and RI in the IR of sentinel lymph nodes. (A) Results prior to grouping ICG doses. (B) Results following grouping of ICG doses. ICG, indocyanine green; RI, radioisotope; IR, identification rate; M-H, Mantel-Haensze.

The near-infrared fluorescence released by the ICG after being excited by infrared light can be imaged using an in vitro device, revealing the shape of the lymphatic vessel and positioning the breast SLN (6). It is a sufficient in vivo imaging tool due to its soft tissue penetration and is less disturbed by natural light (10).

The use of $\mathrm{BD}$ has the advantages of being inexpensive and easy to prepare intraoperatively (12); however, the surgeon needs to rely on vision to locate lymph nodes during tracing. Therefore, the detection rate is more dependent on the surgeon's experience and requires a longer learning curve. Additionally, the low detection rate of SLNs and high
FNR render it an unsuitable tracer agent (10). RI can aid in positioning SLNs by detecting $\gamma$ rays from lymph nodes on the body surface (13). It is superior to BD in detection rate; however, it has an increased surgery cost and complex operation as radioactive tracers need to be injected into the patient the day prior to surgery (10). Furthermore, the subsequent processing of radionuclides limits their use in high-volume centers $(6,12)$.

Although the combined use of BD and RI increases the detection rate of SLNs, the advantages of an inexpensive procedure and rapid localization of lymph nodes do not apply. ICG has the clinical advantages of both BD and 
A ICG test

\begin{tabular}{|c|c|c|c|c|c|c|c|c|}
\hline Study & TP & FP & FN & TN & Sensitivity $(95 \% \mathrm{Cl})$ & Specificity $(95 \% \mathrm{Cl})$ & Sensitivity $(95 \% \mathrm{Cl})$ & Specificity $(95 \% \mathrm{Cl})$ \\
\hline Samorani, 2015 (12) & 70 & 0 & 0 & 513 & $1.00[0.95,1.00]$ & $1.00[0.99,1.00]$ & & \\
\hline Verbeek, 2014 (24) & 22 & 0 & 0 & 155 & $1.00[0.85,1.00]$ & $1.00[0.98,1.00]$ & & \\
\hline Wishart, 2012 (17) & 25 & 0 & 0 & 176 & $1.00[0.86,1.00]$ & $1.00[0.98,1.00]$ & & \\
\hline
\end{tabular}

RI test

Study

Samorani, 2015 (12)

Verbeek, 2014 (24)

Wishart, 2012 (17)
TP FP FN TN

$\begin{array}{llll}55 & 0 & 15 & 382\end{array}$

$\begin{array}{llll}20 & 0 & 2 & 133\end{array}$

$\begin{array}{llll}25 & 0 & 0 & 131\end{array}$

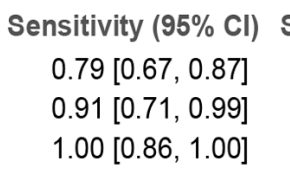

$0.79[0.67,0.87]$

$1.00[0.86,1.00]$

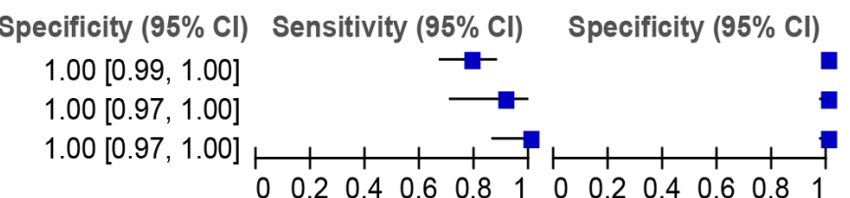

B

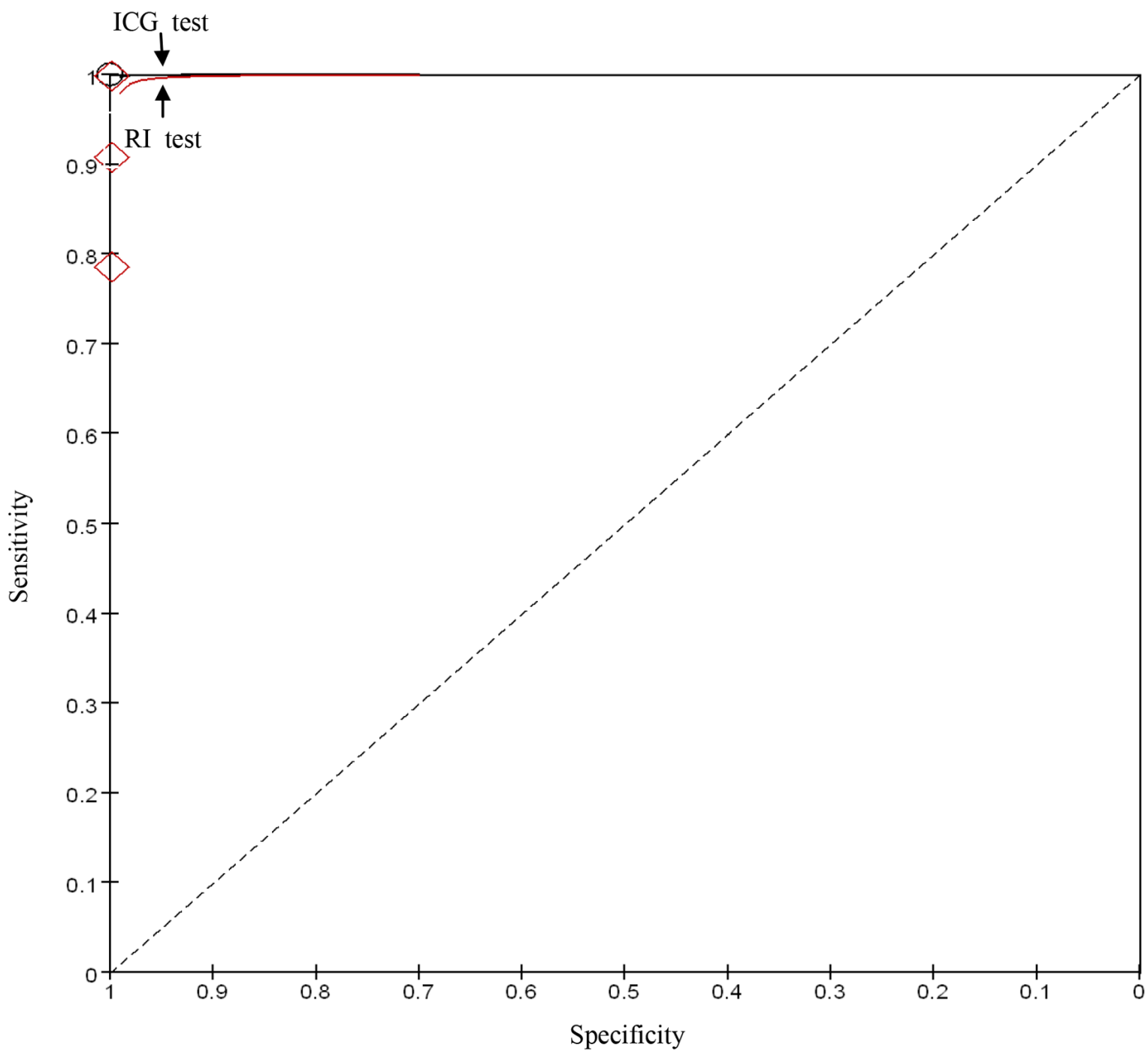

ICG test

RI test

Figure 4. Comparison of the sensitivity and specificity between ICG and RI subgroups. (A) Forest plot of tests and (B) the summary of receiver operating characteristic plot of tests for the two study groups, indicating the accuracy of ICG in lymph node detection was higher compared with that of RI. ICG, indocyanine green; RI, radioisotope; TP, true positive; FP, false positive; FN, false negative; TN, true negative.

RI (14). ICG is a real-time navigation system that can guide the surgical procedure with visible lymphatic drainage using near-infrared fluorescence devices (12). Furthermore, ICG has the advantages of low cost and convenient preparation prior to surgery compared with BD (15). Additionally, ICG has the potential to improve operating room efficiency considering that patients are not required to visit the nuclear medicine department prior to surgery, which may contribute to improved patients experience (12). Although the required dose of RI carries safety concerns for healthcare 


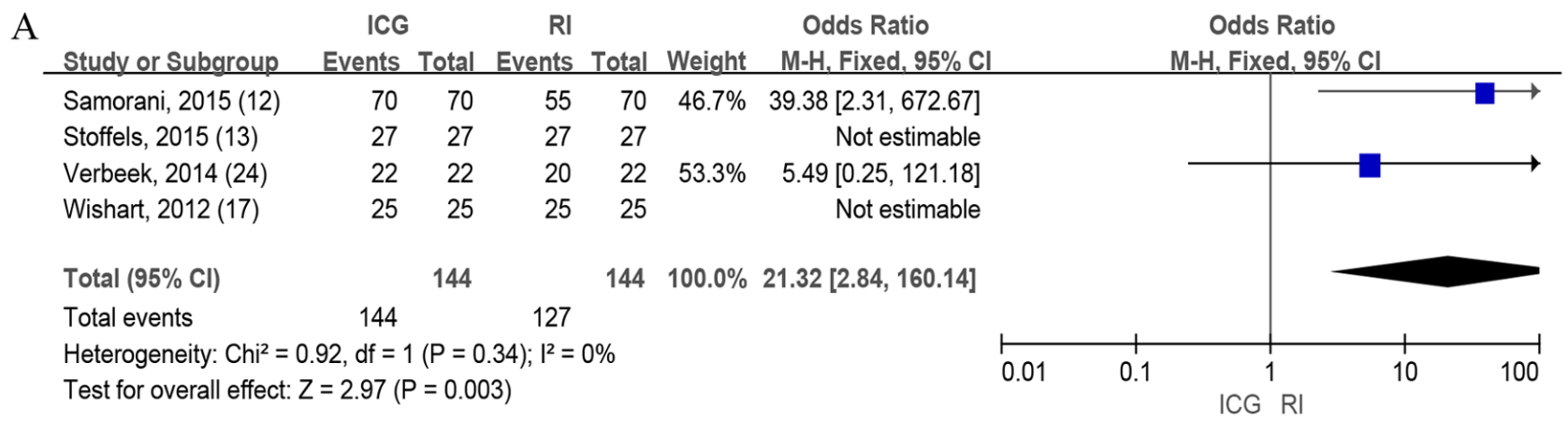

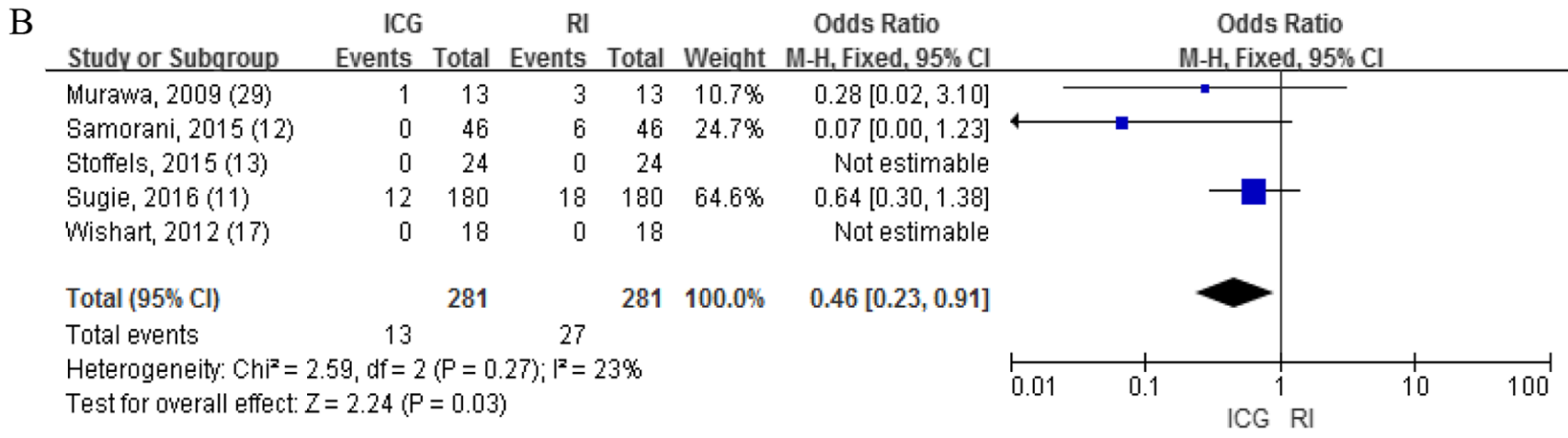

Figure 5. Comparison of ICG and RI in the other outcomes. (A) Comparison of ICG and RI in the identification rate of positive sentinel lymph nodes. (B) Comparison of the false negative rate of ICG and RI. ICG, indocyanine green; RI, radioisotope; M-H, Mantel-Haensze.

professionals, using a non-radiative substance can certainly be an advantage (12).

A meta-analysis by Ahmed et al (5) demonstrated that ICG was superior to BD in with regard to the IR of SLNs. Furthermore, Sugie et al (6) reported that the ICG fluorescence method was better at determining axillary staging compared with the RI method. However, this previous meta-analysis (5) did not agree with the results of the present study, which indicated that ICG was superior to RI in the detection rate of SLNs and the positive SLN detection rate. Additionally, the current meta-analysis indicated that when the dose was limited to the standard dose, there was still a significant difference in the combined OR.

The effect of the ICG dose on the tracer effect has been controversial. Mitsuo et al (31) hypothesized that the concentration and total dose of ICG injection varies depending on the application. For instance, $2.5 \mathrm{mg} / \mathrm{ml}$ concentration and 0.5-1.0 ml ICG are generally used for breast cancer SLN navigation surgery. However, there is certain evidence of improved SLN detection rate at a concentration of $0.5 \mathrm{mg} / \mathrm{ml}$ compared with $2.5 \mathrm{mg} / \mathrm{ml}$ concentration. The present study analyzed the traceability of ICG by dose. The grouping of ICG doses was based on a study by Mieog et al (30), which concluded that the optimal dose of ICG was between 400 and $800 \mu \mathrm{M}$ by assigning patients to different ICG concentration groups of $50-1,000 \mu \mathrm{M}$. As per the study by Mieog et al (30), the grouping of ICG doses is reasonable. The results of the current study demonstrated that using the recommended dose of ICG obtained an improved detection result and the use of a higher dose may cause difficulties in detection due to leakage of fluorescent tracer in lymphatic vessels (14).
The present study has the following differences compared with previous studies. Firstly, the condition of patients being their own controls was incorporated into the inclusion criteria, which avoids bias due to population differences. Secondly, the patient detection rate was differentiated from the SLN detection rate, making the definition 'sentinel lymph node detection rate' more objective. Lastly, different doses of ICG ultimately have different effects on lymph node detection, which provided guidance for the future use of ICG doses.

The present meta-analysis compared ICG with BD combined with RI in breast cancer. The results demonstrated that ICG alone is not significantly different to BD combined with RI in terms of the detection rate of patients and the detection rate of SLNs, indicating that ICG alone is not worse compared with BD combined with RI. Although there was no statistical difference observed in the overall lymph node detection rate using ICG at $100 \%$, this was higher than the $87.88 \%$ of BD combined with RI.

Several limitations in the current meta-analysis should be noted. Firstly, the ICG fluorescence imaging equipment used by the previous studies was not uniform; therefore, data was extracted from studies that used different equipment, including PDE, Mini-FLARE and CCD. Among these, PDE was the most commonly used. However, other equipment have also been used clinically and were able to achieve a high detection rate of SLNs. Secondly, the definition of SLNs varies in different trials. Wishart et al (17) demonstrated that all tracers (including ICG, BD and RI) detected lymph nodes as SLNs, while Sugie et al (18) concluded that intraoperatively palpable lymph nodes, termed para-SLN, should also be classified as SLNs. Other studies (19-21) did not reach the 
A

ICG BD

Odds Ratio

Odds Ratio

Study or Subqroup Events Total Events Total Weiqht M-H, Fixed, 95\% Cl M-H, Fixed, 95\% Cl

Guo, 2014(28) $\quad 80 \quad 86 \quad 70 \quad 86 \quad 42.5 \% \quad 3.05[1.13,8.21]$

Hirano, 2012(19) $\quad 107 \quad 108 \quad 100 \quad 108 \quad 8.1 \% \quad 8.56[1.05,69.67]$

Hojo, 2010(22) $\quad 113 \quad 113 \quad 105 \quad 113 \quad 4.0 \% \quad 18.29[1.04,320.78]$

Jung, 2014(21) $\quad 43 \quad 43 \quad 39 \quad 43 \quad 3.9 \% \quad 9.91[0.52,190.00]$

Liu, 2017 (10) $\quad 60 \quad 60 \quad 53 \quad 60 \quad 3.8 \% \quad 16.96[0.95,304.07]$

Pitsinis, $2015(26) \quad 50 \quad 50 \quad 48 \quad 50 \quad 4.1 \% \quad 5.21[0.24,111.24]$

$\begin{array}{lllllll}\text { Sugie, } 2013(18) & 98 & 99 & 78 & 99 & 6.9 \% & 26.38[3.47,200.50]\end{array}$

\begin{tabular}{lllllll} 
Tong, 2014(16) & 93 & 96 & 83 & 96 & $22.6 \%$ & 4.86 \\
\hline & {$[1.34,17.64]$}
\end{tabular}

$\begin{array}{llllll}\text { Verbeek, 2014(24) } & 12 & 12 & 12 & 12 & \text { Not estimable }\end{array}$

$\left.\begin{array}{lllllll}\text { Wishart, } 2012(17) & 104 & 104 & 101 & 104 & 4.2 \% & 7.21 \\ {[0.37,141.29}\end{array}\right]$

Total $(95 \% \mathrm{Cl})$

$\begin{array}{llll}771 & 771 & 100.0 \% & 7.17\end{array}[3.98,12.94]$

Total events

$760 \quad 689$

Heterogeneity: $\mathrm{Ch}^{2}=5.67, \mathrm{df}=8(\mathrm{P}=0.68) ; \mathrm{I}^{2}=0 \%$

Test for overall effect: $Z=6.54(\mathrm{P}<0.00001)$

B

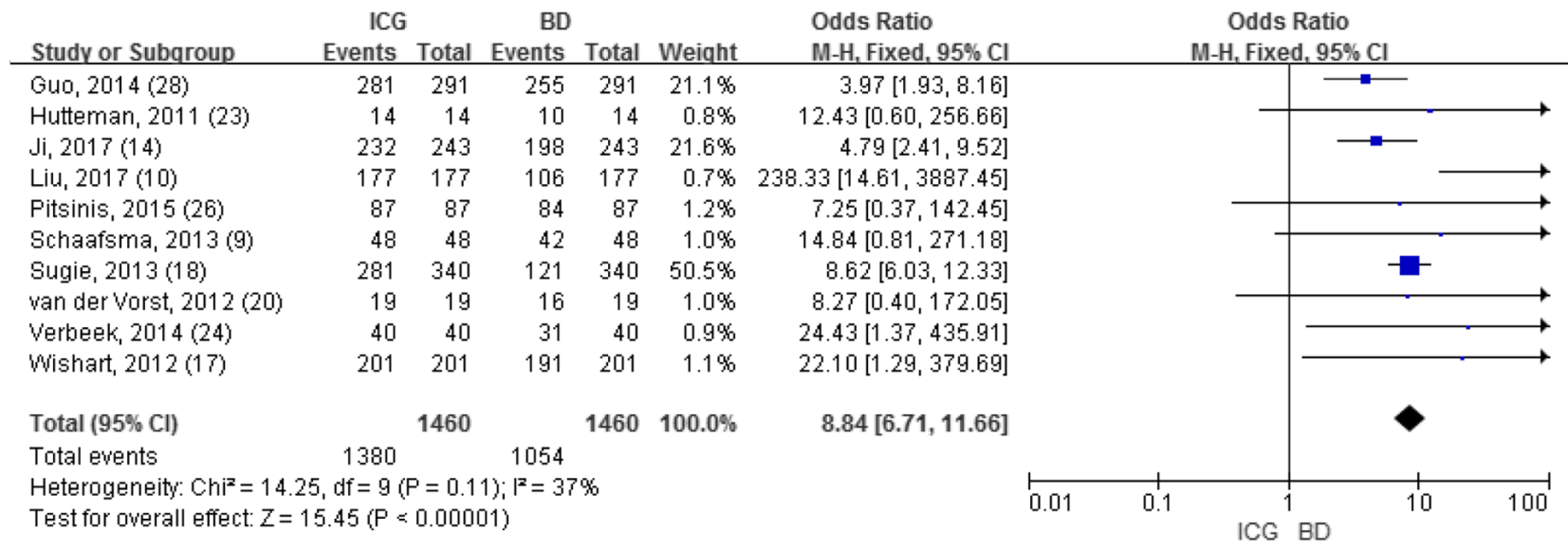

C

ICG BD

Odds Ratio

Odds Ratio

Study or Subqroup Events Total Events Total Weiqht M-H, Fixed, 95\% Cl

$\begin{array}{lllllll}\mathrm{Ji}, 2017(14) & 29 & 31 & 26 & 31 & 85.2 \% & 2.79[0.50,15.62]\end{array}$

Pitsinis, 2015 (26)

Verbeek, $2014(24)$

Wishart, $2012(17)$

$\begin{array}{llll}18 & 18 & 18 & 18\end{array}$

$5 \quad 5$

Not estimable

\begin{tabular}{lllll} 
Total $(95 \% \mathrm{Cl})$ & 79 & 79 & $100.0 \%$ & 3.54 \\
\hline
\end{tabular}

Total events $77 \quad 72$

Heterogeneity: $\mathrm{Chi}^{2}=0.30, \mathrm{df}=1(\mathrm{P}=0.59) ; \mathrm{I}^{2}=0 \%$

Test for overall effect: $Z=1.64(P=0.10)$

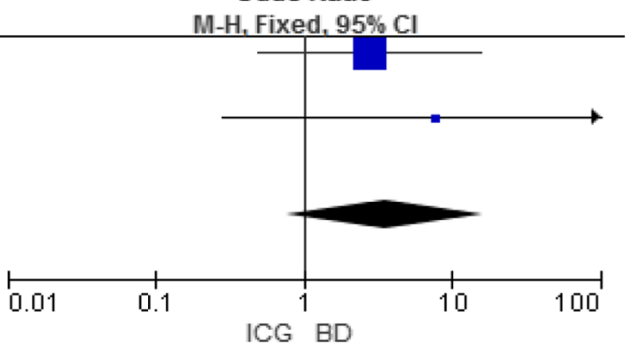

$\mathrm{D}$

\begin{tabular}{|c|c|c|c|c|c|}
\hline \multirow[b]{2}{*}{ Study or Subgroup } & \multicolumn{2}{|l|}{ ICG } & \multicolumn{2}{|l|}{ BD } & \multirow{2}{*}{ Weight } \\
\hline & Events & Total & Events & Total & \\
\hline Guo, $2014(28)$ & 3 & 25 & 4 & 25 & $13.5 \%$ \\
\hline Hirano, 2012 (19) & 1 & 16 & 5 & 16 & $17.9 \%$ \\
\hline Hojo, 2010 (22) & 0 & 31 & 5 & 31 & $20.7 \%$ \\
\hline Pitsinis, 2015 (26) & 0 & 10 & 0 & 10 & \\
\hline Sugie, 2013 (18) & 0 & 20 & 6 & 20 & $24.3 \%$ \\
\hline Tong, 2014 (16) & 1 & 29 & 4 & 29 & $14.8 \%$ \\
\hline Verbeek, 2014 (24) & 0 & 5 & 2 & 5 & $8.8 \%$ \\
\hline Wishart, 2012 (17) & 0 & 18 & 0 & 18 & \\
\hline Total $(95 \% \mathrm{Cl})$ & & 154 & & 154 & $100.0 \%$ \\
\hline Total events & 5 & & 26 & & \\
\hline Heterogeneity: C & $\mathrm{df}=$ & $5(P=$ & $;\left.\right|^{2}=$ & & \\
\hline
\end{tabular}

Odds Ratio

$\mathrm{M}-\mathrm{H}$, Fixed, 95\% Cl

$0.72[0.14,3.59]$

$0.15[0.01,1.44]$

$0.08[0.00,1.45]$

Not estimable

$0.05[0.00,1.04]$

$0.22[0.02,2.13]$

$0.13[0.00,3.52]$

Not estimable

$0.20[0.08,0.48]$

Test for overall effect: $Z=3.57(P=0.0004)$

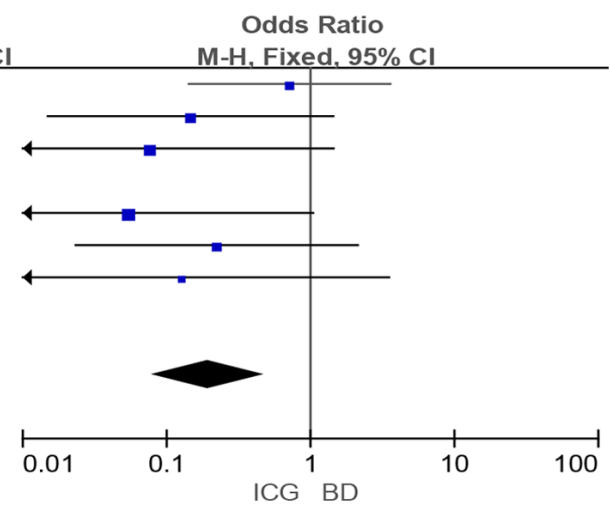

Figure 6. Comparison of ICG and BD in different outcomes. (A) IR of patients. (B) IR of SLNs. (C) Result of IR of positive SLNs. (D) False negative rate results of ICG and BD. ICG, indocyanine green; BD, blue dye; IR, identification rate; SLNs, sentinel lymph nodes; M-H, Mantel-Haensze.

same conclusion. Therefore, altering the intended definition of SLN may lead to certain differences in the detection rate of SLN. Thirdly, the criteria for enrollment for each trial were different, particularly in regard to previous axillary surgery history. Although all patients were clinically node-negative, there were studies that did not specify the exclusion criteria, 
A ICG test

\begin{tabular}{|c|c|c|c|c|c|c|c|c|}
\hline Study & TP & FP & FN & TN & Sensitivity $(95 \% \mathrm{Cl})$ & Specificity (95\% Cl) & Sensitivity $(95 \% \mathrm{Cl})$ & Specificity $(95 \% \mathrm{Cl})$ \\
\hline Ji, 2017 (14) & 29 & 0 & 2 & 203 & $0.94[0.79,0.99]$ & $1.00[0.98,1.00]$ & & \\
\hline Pitsinis, 2015 (26) & 18 & 0 & 0 & 69 & $1.00[0.81,1.00]$ & $1.00[0.95,1.00]$ & & \\
\hline Verbeek, 2014 (24) & 5 & 0 & 0 & 35 & $1.00[0.48,1.00]$ & $1.00[0.90,1.00]$ & & \\
\hline Wishart, 2012 (17) & 25 & 0 & 0 & 176 & $1.00[0.86,1.00]$ & $1.00[0.98,1.00]_{\vdash}$ & 0.40 & \\
\hline
\end{tabular}

BD test

Study

Ji, 2017 (14)

TP FP FN TN

Sensitivity $(95 \% \mathrm{CI})$

Specificity $(95 \% \mathrm{Cl})$ Sensitivity $(95 \% \mathrm{Cl})$

Specificity $(95 \% \mathrm{Cl})$

Pitsinis, 2015 (26)

$\begin{array}{llll}26 & 0 & 5 & 172\end{array}$

$0.84[0.66,0.95]$

$1.00[0.98,1.00]$

Verbeek, 2014 (24)

$\begin{array}{llll}18 & 0 & 0 & 66\end{array}$

$1.00[0.81,1.00]$

$1.00[0.95,1.00]$

$0.60[0.15,0.95]$

$1.00[0.88,1.00]$

$1.00[0.86,1.00]$

$1.00[0.98,1.00]$

$\begin{array}{lllllllllllll}0 & 0.2 & 0.4 & 0.6 & 0.8 & 1 & 0 & 0.2 & 0.4 & 0.6 & 0.8 & 1\end{array}$

B

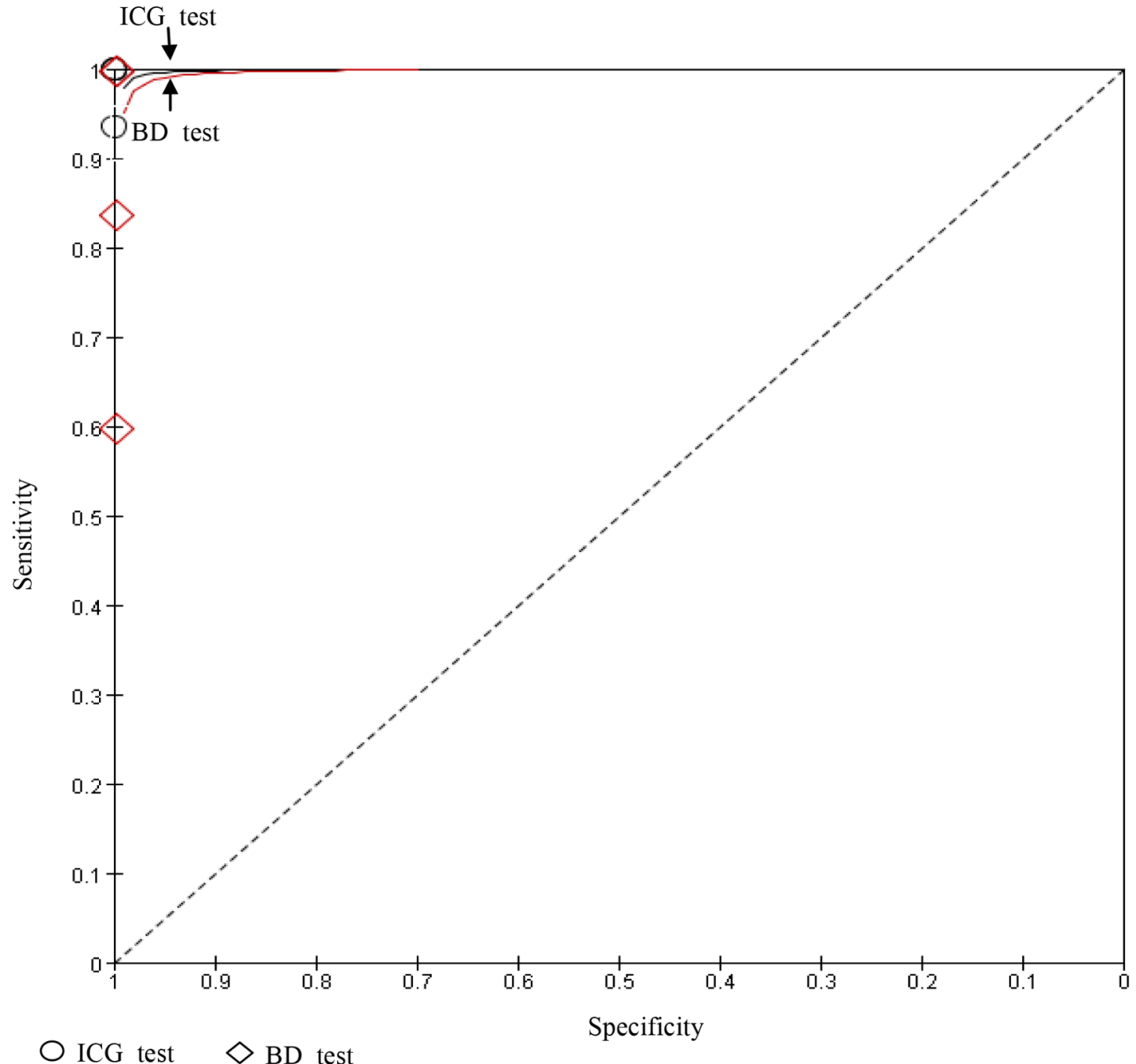

Figure 7. Comparison of sensitivity and specificity between ICG and BD. (A) Forest plot of tests and (B) the summary of receiver operating characteristic plot of tests for the two study groups, indicating the accuracy of ICG in lymph node detection was higher compared with that of BD. ICG, indocyanine green; $\mathrm{BD}$, blue dye; TP, true positive; FP, false positive; FN, false negative; TN, true negative.

making the patients heterogeneous in the present meta-analysis. Lastly, the authors may have missed certain unpublished investigations, considering studies with positive results are usually more prone to being published.

In conclusion, the present comprehensive meta-analysis indicated that using ICG alone is a better tracer agent compared with using $\mathrm{BD}$ or RI alone, and is not worse compared with BD combined with RI. A suitable dose of ICG can increase the detectability and accuracy, and decrease the heterogeneity. Considering the clinical convenience of ICG, it may be used as a suitable alternative to traditional tracers to detect SLNs in patients with breast cancer. 
A

ICG BD and RI

Odds Ratio

Odds Ratio

Study or Subgroup

Events Total Events Total Weight M-H, Fixed, 95\% Cl

M-H, Fixed, $95 \% \mathrm{Cl}$

Hutteman, 2011 (23)

Jung, 2014 (21)

van der Vorst, 2012 (20)

Wishart, 2012 (17)

$10 \quad 10$

Not estimable

Not estimable

4343

$\begin{array}{llll}12 & 12 & 12 & 12\end{array}$

104104

$\begin{array}{rr}12 & 12 \\ 102 & 104\end{array}$

Not estimable

Total $(95 \% \mathrm{Cl})$

169

Total events

169

$169 \quad 100.0 \% \quad 5.10[0.24,107.48]$

Heterogeneity: Not applicable

Test for overall effect: $Z=1.05(P=0.30)$

167

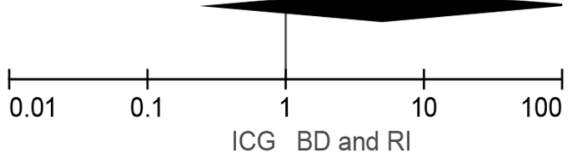

B

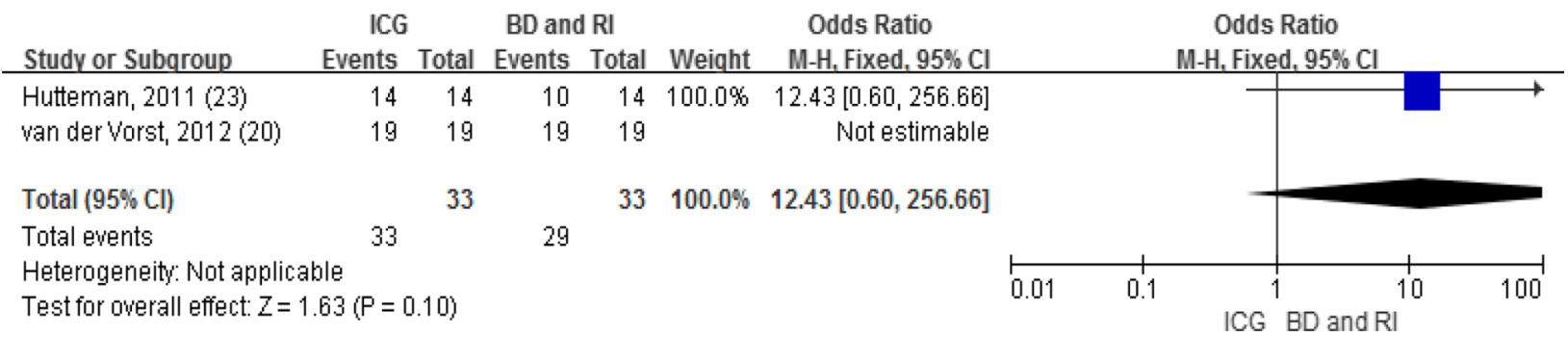

Figure 8. Comparison of ICG and BD combined with RI in different outcomes. (A) IR of patients. (B) IR of sentinel lymph nodes. ICG, indocyanine green; $\mathrm{BD}$, blue dye; RI, radioisotope; IR, identification rate; M-H, Mantel-Haensze.
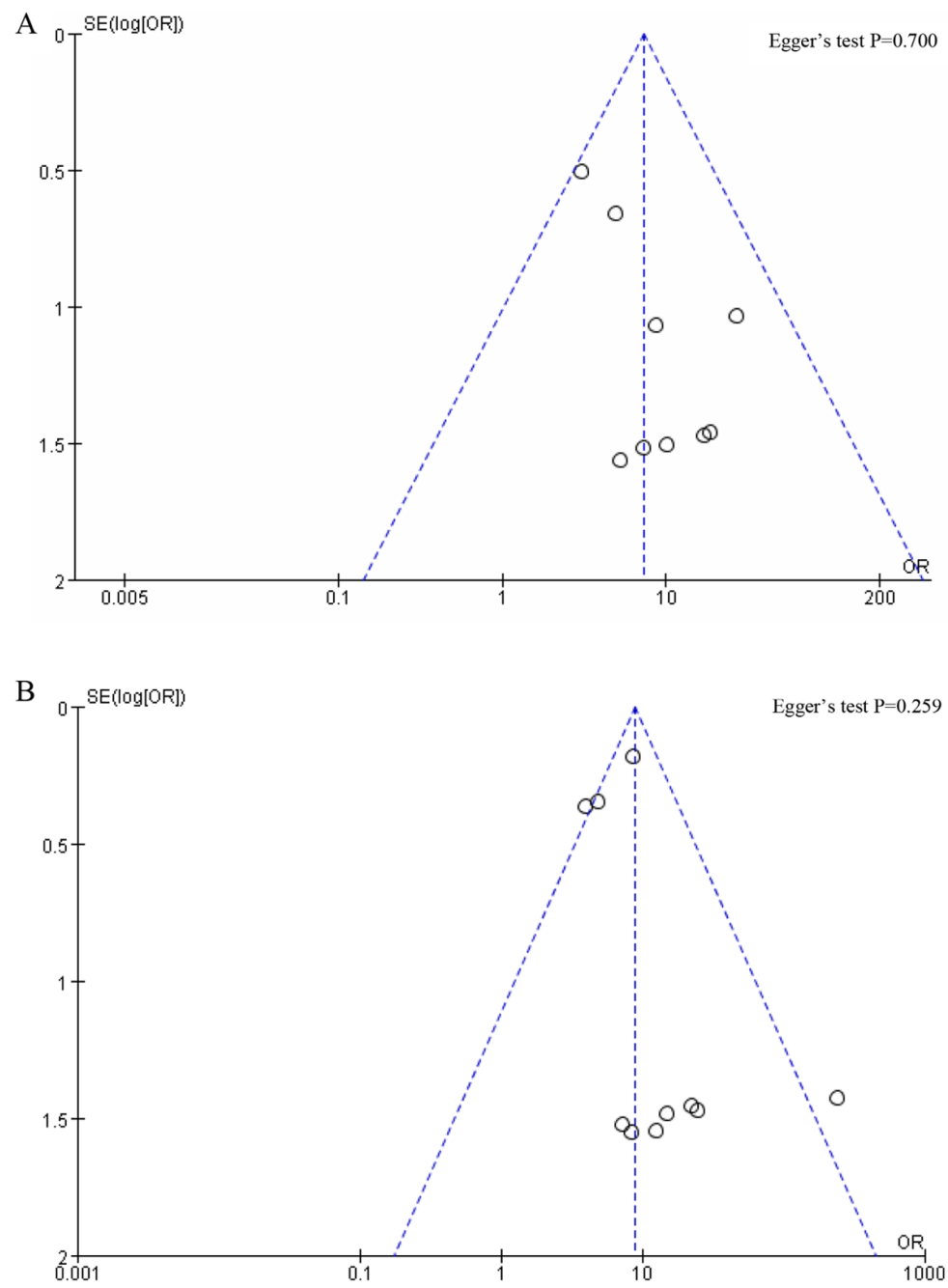

Figure 9. Funnel plots with Egger's test were used to identify publication bias. (A) Result of publication bias in IR of patients and (B) results of IR of SLNs for the two study groups. No obvious publication bias was observed. IR, identification rate. 


\section{Acknowledgements}

Not applicable.

\section{Funding}

No funding was received.

\section{Availability of data and materials}

The datasets generated and/or analyzed during the current study are available from the corresponding author on reasonable request.

\section{Authors' contributions}

RY conceived the current study and collected data. XZ put forward the concept of ICG as a new tracer superior to traditional tracers and helped design the article and gave final approval of the version to be published, participated in the revision of the article, checked the data, provided the final conclusion for the version to be published, provided support for obtaining some documents in the article, provided administrative support and gave final approval of the version to be published. LD, QW, YZ and GT collected, analyzed and interpreted the data. RY drafted and revised the manuscript. All authors read and approved the final manuscript.

\section{Ethics approval and consent to participate}

Not applicable.

\section{Patient consent for publication}

Not applicable.

\section{Competing interests}

The authors declare that they have no competing interests.

\section{References}

1. Mansel RE, Fallowfield L, Kissin M, Goyal A, Newcombe RG Dixon JM, Yiangou C, Horgan K, Bundred N, Monypenny I, et al: Randomized multicenter trial of sentinel node biopsy versus standard axillary treatment in operable breast cancer: The ALMANAC trial. J Natl Cancer Inst 98: 599-609, 2006.

2. Krag DN, Weaver DL, Alex JC and Fairbank JT: Surgical resection and radiolocalization of the sentinel lymph node in breast cancer using a gamma probe. Surg Oncol 2: 335-340, 1993.

3. Giuliano AE, Kirgan DM, Guenther JM and Morton DL: Lymphatic mapping and sentinel lymphadenectomy for breast cancer. Ann Surg 220: 391-401, 1994.

4. Kitai T, Inomoto T, Miwa M and Shikayama T: Fluorescence navigation with indocyanine green for detecting sentinel lymph nodes in breast cancer. Breast Cancer 12: 211-215, 2005.

5. Ahmed M, Purushotham AD and Douek M: Novel techniques for sentinel lymph node biopsy in breast cancer: A systematic review. Lancet Oncol 15: e351-e362, 2014.

6. Sugie T,Ikeda T, Kawaguchi A, Shimizu A and Toi M: Sentinel lymph node biopsy using indocyanine green fluorescence in early-stage breast cancer: A meta-analysis. Int J Clin Oncol 22: 11-17, 2017.

7. Moher D, Liberati A, Tetzlaff J and Altman DG; PRISMA Group: Preferred reporting items for systematic reviews and meta-analyses: The PRISMA statement. Ann Intern Med 151: 264-269, W64, 2009.
8. Stang A: Critical evaluation of the Newcastle-Ottawa scale for the assessment of the quality of nonrandomized studies in meta-analyses. Eur J Epidemiol 25: 603-605, 2010.

9. Schaafsma BE, Verbeek FP, Rietbergen DD, van der Hiel B, van der Vorst JR, Liefers GJ, Frangioni JV, van de Velde CJ, van Leeuwen FW and Vahrmeijer AL: Clinical trial of combined radio and fluorescence guided sentinel lymph node biopsy in breast cancer. Br J Surg 100: 1037-1044, 2013.

10. Liu J, Huang L, Wang N and Chen P: Indocyanine green detects sentinel lymph nodes in early breast cancer. J Int Med Res 45: 514-524, 2017.

11. Sugie T, Kinoshita T, Masuda N, Sawada T, Yamauchi A, Kuroi K, Taguchi T, Bando H, Yamashiro H, Lee T, et al: Evaluation of the clinical utility of the ICG fluorescence method compared with the radioisotope method for sentinel lymph node biopsy in breast cancer. Ann Surg Oncol 23: 44-50, 2016.

12. Samorani D, Fogacci T, Panzini I, Frisoni G, Accardi FG, Ricci M, Fabbri E, Nicoletti S, Flenghi L, Tamburini E, et al: The use of indocyanine green to detect sentinel nodes in breast cancer: A prospective study. Eur J Surg Oncol 41: 64-70, 2015.

13. Stoffels I, Dissemond J, Pöppel T, Schadendorf D and Klode J: Intraoperative fluorescence imaging for sentinel lymph node detection: Prospective clinical trial to compare the usefulness of indocyanine green vs technetium Tc $99 \mathrm{~m}$ for identification of sentinel lymph nodes. JAMA Surg 150: 617-623, 2015.

14. Ji Y, Luo N, Jiang Y, Li Q, Wei W, Yang H and Liu J: Clinical utility of the additional use of blue dye for indocyanine green for sentinel node biopsy in breast cancer. J Surg Res 215: 88-92, 2017.

15. Grischke EM, Röhm C, Hahn M, Helms G, Brucker S and Wallwiener D: ICG fluorescence technique for the detection of sentinel lymph nodes in breast cancer: Results of a prospective open-label clinical trial. Geburtshilfe Frauenheilk 75: 935-940, 2015.

16. Tong M, Guo W and Gao W: Use of fluorescence imaging in combination with patent blue dye versus patent blue dye alone in sentinel lymph node biopsy in breast cancer. J Breast Cancer 17: 250-255, 2014.

17. Wishart GC, Loh SW, Jones L and Benson JR: A feasibility study (ICG-10) of indocyanine green (ICG) fluorescence mapping for sentinel lymph node detection in early breast cancer. Eur J Surg Oncol 38: 651-656, 2012.

18. Sugie T, Sawada T, Tagaya N, Kinoshita T, Yamagami K, Suwa H, Ikeda T, Yoshimura K, Niimi M, Shimizu A and Toi M: Comparison of the indocyanine green fluorescence and blue dye methods in detection of sentinel lymph nodes in early-stage breast cancer. Ann Surg Oncol 20: 2213-2218, 2013.

19. Hirano A, Kamimura M, Ogura K, Kim N, Hattori A, Setoguchi Y, Okubo F, Inoue H, Miyamoto R, Kinoshita J, et al: A comparison of indocyanine green fluorescence imaging plus blue dye and blue dye alone for sentinel node navigation surgery in breast cancer patients. Ann Surg Oncol 19: 4112-4116, 2012.

20. van der Vorst JR, Schaafsma BE, Verbeek FP, Hutteman M, Mieog JS, Lowik CW, Liefers GJ, Frangioni JV, van de Velde CJ and Vahrmeijer AL: Randomized comparison of near-infrared fluorescence imaging using indocyanine green and $99(\mathrm{~m})$ technetium with or without patent blue for the sentinel lymph node procedure in breast cancer patients. Ann Surg Oncol 19: 4104-4111, 2012.

21. Jung SY, Kim SK, Kim SW, Kwon Y, Lee ES, Kang HS, Ko KL, Shin KH, Lee KS, Park IH, et al: Comparison of sentinel lymph node biopsy guided by the multimodal method of indocyanine green fluorescence, radioisotope, and blue dye versus the radioisotope method in breast cancer: A randomized controlled trial. Ann Surg Oncol 21: 1254-1259, 2014.

22. Hojo T, Nagao T, Kikuyama M, Akashi S and Kinoshita T: Evaluation of sentinel node biopsy by combined fluorescent and dye method and lymph flow for breast cancer. Breast 19: 210-213, 2010.

23. Hutteman M, Mieog JS, van der Vorst JR, Liefers GJ, Putter H, Löwik CW, Frangioni JV, van de Velde CJ and Vahrmeijer AL: Randomized, double-blind comparison of indocyanine green with or without albumin premixing for near-infrared fluorescence imaging of sentinel lymph nodes in breast cancer patients. Breast Cancer Res Treat 127: 163-170, 2011.

24. Verbeek FP, Troyan SL, Mieog JS, Liefers GJ, Moffitt LA, Rosenberg M, Hirshfield-Bartek J, Gioux S, van de Velde CJ, Vahrmeijer AL and Frangioni JV: Near-infrared fluorescence sentinel lymph node mapping in breast cancer: A multicenter experience. Breast Cancer Res Treat 143: 333-342, 2014. 
25. Ballardini B, Santoro L, Sangalli C, Gentilini O, Renne G, Lissidini G, Pagani GM, Toesca A, Blundo C, del Castillo A, et al: The indocyanine green method is equivalent to the $99 \mathrm{mTc}$-labeled radiotracer method for identifying the sentinel node in breast cancer: A concordance and validation study. Eur J Surg Oncol 39: 1332-1336, 2013.

26. Pitsinis V, Provenzano E, Kaklamanis L, Wishart GC and Benson JR: Indocyanine green fluorescence mapping for sentinel lymph node biopsy in early breast cancer. Surg Oncol 24: 375-379, 2015

27. Polom K, Murawa D, Nowaczyk P, Rho YS and Murawa P: Breast cancer sentinel lymph node mapping using near infrared guided indocyanine green and indocyanine green-human serum albumin in comparison with gamma emitting radioactive colloid tracer. Eur J Surg Oncol 38: 137-142, 2012

28. Guo W, Zhang L, Ji J, Gao W, Liu J and Tong M: Evaluation of the benefit of using blue dye in addition to indocyanine green fluorescence for sentinel lymph node biopsy in patients with breast cancer. World J Surg Oncol 12: 290, 2014.
29. Murawa D, Hirche C, Dresel S and Hünerbein M: Sentinel lymph node biopsy in breast cancer guided by indocyanine green fluorescence. Br J Surg 96: 1289-1294, 2009.

30. Mieog JS, Troyan SL, Hutteman M, Donohoe KJ, Van Der Vorst JR, Stockdale A, Liefers GJ, Choi HS, Gibbs-Strauss SL, Putter $\mathrm{H}$, et al: Toward optimization of imaging system and lymphatic tracer for near-infrared fluorescent sentinel lymph node mapping in breast cancer. Ann Surg Oncol 18: 2483-2491, 2011.

31. Kusano M, Kokudo N, Toi M and Kaibori M (eds): ICG fluorescence imaging and navigation surgery. Springer, Japan, 2016.

(i) This work is licensed under a Creative Common Attribution-NonCommercial-NoDerivatives 4.0 International (CC BY-NC-ND 4.0) License. 